to expect a monthly prescription in excess of $£ 100$ ? In many of these situations the general practitioner would find himself in the position of having to choose between the care of his patients and being able to retain his legitimate income for his own and his family's use.

Too heavy a burden of sanctions must only act to increase the internal conflict that a practitioner accepts in undertaking to look after an NHS list of patients. This must lead to an attrition of good service and to bad feelings. This, I would predict, would be soon discernible from the retirement, emigration, and suicide rates of general practitioners. The very complexity of the pool system makes it difficult to reward the careful rather than the lazy doctor. Simplistic attempts to use financia incentives within that system can easily have very different effect from what was intended.

\section{A R DEwsBury}

\section{Birmingham}

Clinical Practice in its Economic Context, ed C I
Philips and J N Wolfe. London, Pitman, 1977.

\section{A tennis elbow support}

SIR,-I was interested to read the letter by Mr S C Chen (1 October, p 894) on the tennis elbow support. His preliminary results are impressive, but I would like to point out that an almost identical support has been described elsewhere, ${ }^{1}$ with similar encouraging results.

ANTHONY J RICHARDS

Department of Rheumatology,

Worthing Hospital,

Sussex

'Froimson, A I, fournal of Bone and foint Surgery,
1971, 53-A, 183.

\section{Bell's palsy and herpes simplex}

SIR,-Dr P Grout (24 September, p 829) describes a patient who had facial nerve palsy and stomatitis. It is postulated that the motor nerve palsy was due to herpes simplex virus. The evidence for this is quite inadequate. There is no substantive evidence that the stomatitis was due to herpes simplex, and only positive cultures could have proved that. W are told that there were "very high antibody titres to HSV and varicella-zoster (V-Z)" but we are not told what the titres were.

Dr F O MacCallum and I investigated many patients with Bell's palsy, but we never found any evidence that it was due to herpes simplex virus. This does not mean to say that it could not happen. Facial palsy certainly can be part of the picture of herpes simplex virus encephalitis. Stomatitis in encephalitis must be extremely rare, as it is practically never possible to recover the virus from sites outside the central nervous system. On the other hand facial palsy is perhaps the commonest form of $\mathrm{V}-\mathrm{Z}$ motor nerve involvement, alone or in association with sensory zoster. We are told that there were paraesthesiae in the area of the Vth nerve. As mentioned above, we were not told what the titre of antibody to $\mathrm{V}-\mathrm{Z}$ was, but I would submit that it is far more likely that Dr Grout's patient's motor palsy of the facial nerve was due to $\mathrm{V}-\mathrm{Z}$ virus than to herpes simplex virus. This does not preclude the possibility that the patient also had herpes simplex stomatitis, but without paired sera or positive cultures we shall never know. We were not told if the lesions were unilateral; if they were it is possible that the lesions in the mouth could have been due to zoster of the maxillary and mandibular divisions of the trigeminal nerve.

BENT JUEL-JENSEN

Radcliffe Infirmary,

Oxford

\section{Questionnaires and abuse of privacy}

SIR,-A short time ago I received a letter and questionnaire from the Medical Care Research Unit, Department of Community Medicine, University of Sheffield Medical School. The letter explained that research was being done into the problems that women face in pursuing their careers. On turning to the questionnaire I read the questions with growing disbelief. Not only was I expected to identify myself and every detail of my career completely, I was also expected to identify my parents and their occupations, and details of my husband's career if he happened to be a medical doctor.

How dare anyone under the excuse of research make such an invasion of one's privacy! Surely the answers to the problems (if any) of women in medicine can be obtained by other questions or methods. I have protested by letter to the person who sent out the questionnaire. I hope that all the other women doctors who have received such requests have either ignored them or, better still, protested as I have done. There are too frequently such blatant abuses of privacy at the present time.

Fleetwood, Lancs

Aline Sullivan

\section{Vitamin $B_{12}$ deficiency in a child}

SIR,-I was interested to read of the case of vitamin $\mathrm{B}_{1,2}$ deficiency in a child described by Dr D Attock and his colleagues (24 September, p 807). I find it surprising that a jejuna biopsy was not performed since $\mathrm{B}_{12}$ deficiency occurs commonly in coeliac disease. ${ }^{1}$ Lack of steatorrhoea," normal small-bowel radiology, and normal serum levels of folate, calcium phosphate, magnesium, and vitamin A do not exclude the diagnosis of coeliac disease. ${ }^{4}$

Using a paediatric small-intestinal biopsy capsule jejunal biopsy is a safe procedure and is not distressing to children when performed with a suitable introducer and using intravenous diazepam and metoclopramide. Indeed, by screening the position of the capsule with an image intensifier jejunal biopsy can often be performed within 5-10 minutes. It seems a pity not at least to exclude the diagnosis of coeliac disease in patients with malabsorption of $B_{1 .}$ since the condition can be readily treated with a gluten-free diet and the longterm complications of the undiagnosed disease avoided.

General Hospital,

R FERGUSON

General Hospita
Nottingham

'Hoffbrand, A V, in Clinics in Gastroenterology: Coeliac Disease, ed W T Coc

McNeish, A S, and Anderson, C M, in Clinics in Gastroenterology: Coeliac Disease, ed W T Cook and P Asquith, p 131. London, Saunders, 1974. ${ }^{3}$ Burrows, F G O, and Toye, D K M, in Clinics in Gastroenterology: Coeliac Disease, ed W T Cooke and $P$ Asquith, $p 104$. London, Saunders, 1974.

Ferguson, R, MD Thesis, University of Birmingham
Mobilisation after myocardial infarction

SIR,-Your leading article on this subject (10 September, p 651) states that the benefit of "a formal programme of physical training in a physiotherapy department or gymnasium" should be set against "the expense and time, the high drop-out rate, and the uncertainty that the long-term prognosis is improved."

This hospital has been offering a physical training programme to selected patients after myocardial infarction over the past seven years and the only expense incurred is the salary of a part-time physiotherapist, the medical staff being on call to the coronary care unit. ${ }^{1}$ The patients and their wives have been enthusiastic about the service and feel that it has improved their morale, physical fitness, and capacity both to work and to follow leisure pursuits.

We feel that there is no reason why a district hospital with coronary care responsibility should not offer this valuable and economic service.

D MCC BOYLE

J M BARBER

PATRICIA MCCOY

Ulster Hospital,

Belfast

Singh, N S, et al, fournal of the Irish Medical Associa-

Immunological deficiency, cancer, and prostaglandins

SIR,-Your leading article (10 September, p 654) expressed the hope that fundamental research may one day enable some form of biological engineering to correct the fault in congenital immunodeficiency disease. We suggest that in one form of immunodeficiency disease such "engineering" has been successfully used since 1953. The failure of research workers to recognise this is an interesting example of the danger of specialisation.

Acrodermatitis enteropathica (AE) is a congenital disease which presents soon after birth with severe acral dermatitis, total alopecia, and gastrointestinal disturbances. The skin disorder usually ensures that affected infants are referred to a dermatologist, who recognises $\mathrm{AE}$ and prescribes dihydroxyiodoquin, penicillamine, or zinc. Dihydroxyiodoquin was empirically found successful in $1953,{ }^{1}$ while the use of penicillamine was reported in 1963. More recently AE was found to be associated with zinc deficiency and zinc seems to produce a complete symptomatic cure. ${ }^{3+}$ Patients with $\mathrm{AE}$ have therefore no reason to be seen by specialists in immunodeficiency disease.

It is only on reading papers written by those who attempted to treat the disease before 1953 or who have had experience of a patient with AE which was not diagnosed as such until a late stage that the connection between $\mathrm{AE}$ and immunodeficiency can be appreciated. Untreated $\mathrm{AE}$ is associated with total or neartotal absence of the thymus, hypotrophic or absent tonsils, Peyer's patches, and peripheral lymph nodes, and evidence of both $\mathrm{T}$ and $\mathrm{B}$ lymphocyte deficiency." "There are multiple infections difficult or impossible to treat with antibiotics. Candida and pseudomonas are common infecting organisms and in several cases which came to necropsy the described lung changes were consistent with Pneumocystis carinii infection. 711

It seems to us therefore that $\mathrm{AE}$ is a form of immunodeficiency disease which, with its 
combination of alopecia and failure of thymus and lymphoid tissue development, shows parallels with the nude mouse, the most widely used experimental model of immunodeficiency disease. The astonishing feature of $\mathrm{AE}$ is the relative ease with which the immunological and other disorders can be pharmacologically corrected. We believe that this may prove to be of the utmost importance for the understanding and treatment of both immune disorders and cancer.

What is the explanation for the immune disorders in AE? The regulation of cytoplasmic calcium concentration is probably crucial in the activation of lymphocytes. ${ }^{12} \mathrm{We}$ have shown that in both vascular smooth muscle and lymphocytes there is an antagonistic relationship between adenosine and prosta glandin(PG)-like substances. ${ }^{13} \quad$ With an elevated adenosine: $P G$ ratio release of intracellular calcium is reduced and cell activation fails. We have argued that this is the basis for the immunological failure in adenosine deaminase deficiency. ${ }^{13}$ In AE there is a failure of normal PG synthesis ${ }^{14}$ and in vitro clinically relevant concentrations of both zinc and penicillamine increase production of a substance with the characteristics of $\mathrm{PGE}_{1} \cdot{ }^{15} \mathrm{AE}$ may therefore also be due to an elevated adenosine:PG ratio, this time due to $P G$ deficiency rather than excess. Progress in cancer and immune disorders may depend on better understanding of the intracellular rela tionships between calcium, adenosine, and prostaglandins.

\section{F HORROBIN \\ M S MANKU \\ R A KaRMALI \\ R O MORGAN \\ A I Ally \\ M KARMAZYN}

Clinical Research Institute of Montreal,

Montreal, Quebec

Dillaha, C J, Lorincz, A L, and Aavik, O R, Fournal of the American Medical Association, 1953, 152, 509 . Javett, S N, Lancet, $1963,1,504$.

Moyarhan, E J, Lancet, 1974, 2, 399.

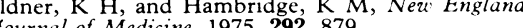
Fournal of Medicine, 1975, 292, 879

ican fournal of Clinical Pathology, 1969, 51, 315

Julius, R, Schulkind, M, and Sprinkle, T, fournal of Pediatrics, 1973, 83, 1007.

Danbolt, N, and Closs, K, Acta Dermato-Venereologica, $1943,23,127$.

Danbolt, N, Acta Dermato-Venereologica, 1956, 36, 257.

Bloom, D, New York State Medical fournal, 1960, 60,

Wells.

s, B T, and Winkelmann, R K, Archives of Dermatology, 1961, 84, 40

Archives of Dermatology, 1974 110,711

Berridge, $M$
$1975,6,1$.

Ally, A I, et al, Prostaglandins, 1977, 14, 109.

Evans, G W, and Johnson, P, Lancet, 1977, i, 52

Horrobin, D F, et al, British Medical fournal, 1977, 2

\section{Release of copper from intrauterine contraceptive devices}

SIR,- The paper by Dr E Chantler and others (30 July, p 288) would have been better entitled "Release of copper from copperbearing contraceptive devices in vitro." The title at present gives an immediate impression that the devices tested had been in utero. It has been shown by Gibor et al in 2788 women in a dose-related study that $200 \mathrm{~mm}^{2}$ of copper on a device is an optimum surface area for contraception. Areas greater than this showed very little reduction in the pregnancy rate.

In their discussion Dr Chantler and his colleagues use the findings of in-vivo trials to substantiate their in-vitro studies and come to the conclusion that "the long-term use of
IUDs dependent on copper for their contraceptive action is of dubious value." I do not think this can be accepted. Moreover, the clinical findings of Newton et al ${ }^{2}$ were recently questioned by Dr I Sivin (6 August, p 387) and may not therefore provide the clinical confirmation implied. The devices studied by Gosden et $a l^{3}$ were removed from patients after being in utero for varying periods of time, and they found that some individuals laid down calcareous deposits more readily than others. The calcium deposit is porous and to what extent it reduces copper elution is not as yet readily known. With present clinical knowledge it appears that the continued elution rate is obviously sufficient for a contraceptive effect. This is supported to some extent in a recently published study by Larsson and Hamberger, ${ }^{4}$ in which they measured the concentration of copper in human uterine secretion during four years after insertion of a copper-containing IUD. In this clinical situation they found no significan reduction in concentration of copper in the uterine secretions during the first four years after insertion. Moreover, no pregnancy or increase in side effects was noted in these women.

Do these in-vitro studies have a great relevance to the clinical situation? In the fina analysis, the proof of the pudding is in the eating; and I do not think anyone has yet satisfactorily shown, with any clinical study, that the pregnancy rate is significantly increased when copper IUDs have been left in utero for more than two years. Even the Food and Drug Administration accepts a three-year claim.

Maurice Cohen Medical Director, High Wycombe, Searle Laboratories Bucks ' Gibor, Y, et al, fournal of Reproductive Medicine, 1973,
11,209 .
2 Newton, J, et al, British Medical fournal, 1977, 1, 197.
' Gosden, C, Ross, A, and Loudon, N B, British Medical
Zournal, 1977, 1, 202. Larsson, B, and Hamberger, L, Fertility and Sterility,
1977, 21, 624.

\section{Effect of oestrogens on postmenopausal} bone loss

SIR,-Professor B E C Nordin's group have confirmed the view that oestrogen therapy prevents postmenopausal loss (Dr A Horsman and others, 24 September, p 789). This has previously been suggested by at least two prospective trials ${ }^{1-3}$ and one non-interventionist Canadian study. ${ }^{4}$ The evidence provided by these centres was considered at a meeting of the Endocrinology and Metabolism Advisory Committee of the Food and Drug Administration in February of this year. This committee concluded that substantial evidence existed that oestrogens were effective in the prevention of bone loss in postmenopausal women, a conclusion with which Dr Horsman and his colleagues happily concur. In addition to showing the beneficial effects of oestrogen Heaney and Recker $^{4}$ also demonstrated that calcium therapy results in partial prevention of bone loss, a result with which this most recent paper also agrees.

We think that if a critical committee of the FDA has accepted that oestrogens prevent bone loss in postmenopausal women it is likely that they are indeed effective. At least one authoritative textbook states categorically that Koch's postulates for the causation of disease are satisfied: "Estrogen deficiency causes; estrogen prophylaxis prevents it; and estrogen replacement stops progression of the disease."

What is needed is information about the effect of such oestrogen replacement on the complications of bone loss characterised by fractures. Additional prospective trials are required to obtain the minimum effective dose of both the synthetic oestrogens and those unhappily called "natural" oestrogens. Attention has to be focused also on the various progestogens and any effect they may have on bone, both by themselves and in combination with oestrogen. This is particularly important since the majority of postmenopausal women who are going to be provided with oestrogen will have intact uteri and should be prescribed a progestogen at least cyclically to induce endometrial shedding and prevent abnormal hyperplasia and possible neoplastic change. This will continue to be so unless we find an oestrogen or a dose of oestrogen which is effective so far as bone loss is concerned but fails to stimulate endometrial growth.

This most recent contribution quotes our original publication ${ }^{1}$ demonstrating the effect of mestranol given to oophorectomised women and correctly quotes our conclusion from that paper that therapy delayed until six years after oophorectomy is ineffective. However, our data have since been updated and many of these patients followed up for five years. ${ }^{2}$ In this subsequent publication, not quoted by Dr Horsman and his colleagues, we have demonstrated that our original failure to show a significant effect in that group of patients in whom therapy had been delayed for six years was due to the small number of patients and the short follow-up period. We have no doubt that oestrogen therapy is effective in preventing bone loss when prescribed at any stage in the postmenopausal era; moreover, when treatment is delayed we have demonstrated a significant increase in bone mineral content estimated by a photon absorptiometric technique), which corresponds to their conclusion that oestrogen "may have stimulated subperiosteal bone apposition."

R LINDSAY

University Department of Medicine, Western Infirmary,

Glasgow

D M HART

Division of Obstetrics and

Gynaecology,
Stobhill General Hospital,

Glasgow

'Aitken, J M, Hart, D M, and Lindsay, R, British Medical fournal, 1973, 2, 515

Lindsay, R, et al, Lancet, 1976, 1, 1038

Heaney, R P, and Recker, R R, Clinical Research, 1975, 23, 535 .

Meema, S, Bunker, M L, and Meema, N E, Archives of Internal Medicine, 1975, 135, 1436.

Gordan, G S, and Vaughan, C V, Clinical Management of the Osteoporoses.

\section{Tietze's syndrome}

SIR,-In contrast to Dr G V Gill's report of Tietze's syndrome in Zambia (20 August, p 499) I have found this syndrome to be quite common in Finland. I see about two to three cases a month in a district hospital of 200 beds and covering a population of 80000 people.

In Finland, where coronary heart disease is common and where people are very sensitive about their thoracic pains, most patients with Tietze's syndrome present themselves in the emergency room believing that they have a heart attack. Careful palpation of the thoracic 